\title{
THE PHANTOM LIMB
}

\author{
By J. Donaldson Craig, M.D., M.R.C.P. \\ Research Fellow in Medicine, St. Mary's Hospital Medical School
}

\section{Introduction}

That an amputated limb which has long since disintegrated should be appreciated in the consciousness of its former owner and even give rise to severe symptoms is, at first sight, a concept so strange that it is hardly surprising that for many years the phantom limb phenomenon was largely ignored in the medical literature and, even now, does not receive the wide recognition which it deserves. No less to the patient than to the observer, the idea appears absurd and therefore, in response to casual questioning during routine inspection of the stump, the patient is liable to reply that all is well, preserving silence on the matter of his symptoms for fear of appearing ridiculous. Yet in reply to direct and sympathetic questioning in privacy, rather than in the hurlyburly of an out-patient clinic, almost all of these people will freely admit to symptoms of varying severity. They do so with considerable and obvious relief that the experiences which they had perhaps regarded as imaginary or neurotic, should be accorded the same status and reality as symptoms arising from any other disease process.

The pattern of these subjective phenomena is remarkably constant, and must have been experienced since the days when amputation was first successfully performed. In primitive communities phantom pain following amputation has been accepted at face value as a reality. When the ' wound ' which occasioned the original loss of the limb continued to be 'painful,' or if the 'limb' were felt in an uncomfortable position, the lost member was disinterred, rearranged in a more comfortable position, and the wound dressed with suitable medicaments. Nelson remained conscious of his fingers after the loss of the arm and maintained that this proved the existence of his soul.

During the age of 1 th century materialism, when reality was accorded only with reluctance to that which was demonstrable, it was perhaps inevitable that these phenomena should receive scant attention. The growth of modern psychiatry has laid more stress on that which is neither visible nor appreciable by the ordinary senses and it became equally inevitable that the phantom limb should be explained as a product of disturbed psychological function, and the distressing symptoms following amputation are believed by many to represent an obsessional neurosis. So many of the occurrences of everyday life and medicine can be explained with such facility in terms of present day psychiatry that it becomes pitifully easy to fall into the error of attributing to disturbances of the psyche, any symptoms for which no organic factor is readily demonstrable. The error is made doubly easy by the development of secondary anxiety and other psychological disorders in those who have long suffered the tiresome symptoms which, to the patients, may not appear to have been treated with the seriousness they merit. The fact remains that psychotherapy per se in such cases is of little value.

The more or less constant pattern of symptoms, the disappointing results of psycho-therapy and the presence of obvious nerve lesions in these patients should effectively discourage any attempt to explain the phantom limb phenomenon on the basis of a neurosis within the strict and limited sense of the term.

Sherrington showed that the central nervous system can no longer be regarded as a series of independent neurones resembling a somewhat complex telephone exchange and therefore to be comprehended in mechanical terms. Rather is it an infinitely complicated dynamic and organic whole, flexible and labile, which in the face of injury or disease will establish a new integration, arriving at its goal, if need be by the use of new and less direct pathways. Mutilation of the body as by amputation therefore produces less disturbance than might be expected on the basis of mechanical concepts. The arm or leg may be as dead as John Brown's body, yet in the sensorium it may still live.

Nerve endings, sharing in this attempt to resist the mutilation and restore the status quo ante begin to regenerate, but the local anatomical changes prevent normal growth and result in the formation of bulb neuromata which, with the proximal ends of the cut nerves intact may receive pain stimuli. Like the less unpleasant sensations which occur more commonly, pain so developing is felt in the phantom. 


\section{The Body Image Concept}

Head and Holmes postulated the existence in the sensorium of a 'body image' in terms of which all sensation is registered, all bodily movements initiated. Riddoch, amplifying this concept, suggested that there were three body images, visual, sensory and motor, all being normally integrated into a whole, compound body image. Clearly amputation partly destroys the visual image but the sensory and motor elements survive and accordingly the lost limb is still ' felt,' and can be 'moved.' Further, pain arising in its territory is interpreted as coming from the lost limb. The fingers, elbow and wrist, having the greatest cortical representation and being the most fully trained parts of the member, are most deeply rooted in the memory of the sensorium, and accordingly it is of these parts that impressions are most vivid and to these parts that pain, when felt, is most. projected. Generally speaking, the lost limb is 'felt' in a comfortable position of relaxation but occasionally it is experienced in the fixed position in which it was last really known to the patient. For example, Leriche records the case of a woman who lost her arm in consequence of a motor accident, her last conscious memory being of the blood-covered limb thrust through the windscreen. After amputation the arm was ' felt' as being fixed in the outstretched position. Livingstone records several very similar cases. Here, it seems, a vivid, powerful impression of the limb had been registered in the sensorium, ousting by its strength the more normal body image developed from all previously accumulated experience. How far psychotherapy might benefit this type of case is a matter for conjecture, but an emotional catharsis might act in the same way as, one presumes, the powerful suggestive influence of magic acts when the savage restores to a more comfortable position his disinterred limb. No such case has been encountered in the present series but the experience of a surgical colleague is directly analagous. He writes as follows :-

' About three years ago I had to have a cartilage removed from my right knee, and the operation was performed under spinal. The surgeon kindly acquiesced to my desire to see what was going on, and I was allowed to lie on the table propped up in a semi-sitting position, with a mirror arranged to reflect the operation site for me.

' The proceedings started-after the injection of anaesthetic-with the application of an Esmarch bandage to my right leg, which was held up vertically for the purpose. The anaesthetic had not yet become fully operative while this was going on, and I had a faint sensation of tightness in the leg, but this rapidly passed off. The leg was then lowered, the knee flexed over the end of the table, and the operation begun. I can still clearly remember my surprise as I watched in the mirror, the knife cut into my knee-not because it was painless, for I had had several minor operations under local analgesia, and was used to the feelingbut because, in spite of being able to view the whole proceeding in comfort, I had difficulty in convincing myself that my leg was not still up in the air where I had last felt it. The leg being operated upon did not seem to bellong to me at all. So vivid was this sensation of my leg being still up in the air that when, having allowed my attention and my eyes to wander round the theatre, I looked in the direction. where my leg had been, I felt a shock at not seeing it there clearly, and indeed almost convinced myself that I could distinguish a ghostly outline.

' This sensation persisted throughout the operation, and continued after my return to the ward until normal sensation began to come back to the limb.'

Generally, with the passage of time, the limb ' shrinks.' Formerly of normal or nearly normal length, it may now be only a few inches long, represented only by the fingers and joints. This evolution is not to be explained as a result of local alterations but in terms of change in the body image. The ability to feel and move a nonexistent limb generally serves no useful purpose and the loss of visual impulses aids in the shrinking of the sensory and motor images. The central nervous system possessing a great faculty for adaptation, the cortical elements formerly serving the lost limb now cease to abrogate themselves to functions rendered impossible by events outside the nervous system.

\section{Phantom Limb Causalgia}

During this period of adjustment, some degree of pain is generally felt in the phantom. This is diffuse and frequently described as cramp-like or burning, particularly when the phantom is appreciated as being fixed in an uncomfortable position. Progressively this pain becomes less severe and less frequently experienced until a year or two after the injury it usually ceases to cause more than slight annoyance.

There remain, however, an unfortunate minority (of which patient five is an example) in whom there develops what is essentially a causalgic state. Pain is then severe. The stump is often cold, anhydrotic or hyperhydrotic, cyanosed or red, oedematous or shrunken. Uncontrollable spasmodic movements may occur, accompanied by stabs of pain, but none of these findings is invariable. Tender neuromata may be present or the stump may present no obvious abnormality. In such instances permanent benefit may follow 
sympathectomy or interruption of the sympathetic pathways by procaine infiltration, but excision of neuromata or neurectomy provide only transitory relief. It is frequently accepted that these pains are caused by pressure on neuromata and for this reason it has been urged that nerves should not be shortened since neuromata forming after such shortening are more liable to pressure from artificial limbs. Neuroma formation is, however, an invariable sequel of amputation and there is no apparent correlation between the size and distribution of neuromata and the amount of pain felt. Clearly, then, some other mechanism operates and there appears to be no essential difference between these severe phantom pains and those which sometimes follow partial or complete section of a peripheral nerve and have been described by Weir Mitchell as causalgia.

Lewis (1936) considered that causalgia was caused by impulses from the distal cut end of the nerve releasing substances in the skin and producing a condition of erythralgia. This explanation is not valid in the present instance for the simple reason that there is no distal nerve ending, and so pain impulses must arise from the proximal end of the nerve trunk or from a related nerve system such as the sympathetic. Further, as shown by Nathan (1947), the skin is not erythralgic in causalgia. It is therefore tempting to suppose that either causalgia is caused by abnormal sympathetic activity or that the pain is carried by sympathetic fibres. There is no evidence that sympathectomy in any way affects sensation in the limbs, although there is some support for the'view that deep pain conduction can occur via the sympathetic system. There is no doubt whatever that in a large proportion of cases of causalgia sympathetic interruption can relieve pain and that even when this interruption is temporary, as by procaine injection, relief may be prolonged. It has been suggested that the action is the interruption of a vicious circle (Leriche, I940 ; Livingstone, 1943), and both vasodilatation and vasoconstriction have been incriminated. Yet in cases of causalgia no particular vascular change can be constantly demonstrated, save a general increase in the blood flow to the affected limb (Leriche and Fontaine, 1929), nor can the pain be constantly affected by measures affecting the vascular state, such as reflex vasodilatation. Further, the vascular changes occurring in causalgia are not confined to this condition. There is a very wide fluctuation in the blood flow to the limb in exercise, climatic extremes and disuse from any cause, including hysteria, all conditions generally painless. It is therefore much more probable that the variable vascular changes in painful stumps and causalgic limbs are purely secondary effects and not causal disturbances. Doupe, Cullen and Chance (1944) therefore concluded that causalgia results from the stimulation of peripheral nerve endings by sympathetic fibres at the point of damage. Action current studies by Granit. Leksell and Skoglund (1944) have shown the possibility of transmission of impulses from motor to sensory nerve-and vice versa at the ' artificial synapse' where a nerve is cut across, ligatured or mechanically compressed. Transmission occurs much more easily from motor to sensory fibre than in the reverse direction and the effect is facilitated in a freshly damaged region. The effect is far more pronounced in the proximal. than in the distal portion of $\dot{a}$ nerve and this observation may have a bearing on the recognized fact that phantom pains are more likely to be severe after high rather than low amputations. The relief from sympathectomy and the aggravation by excessive heat or cold and by emotional stress can thus be understood, since all these latter influences increase sympathetic activity. Likewise pain, in itself a stimulant of the sympathetic system (Cannon, 1929), may reflexly aggravate or maintain peripheral pain. In this respect at least, causalgia may be regarded as the produce of a vicious circle, and it is easy to see how permanent pain may result from excessive handling of the stump during convalescence, necessarily painful, or from excessive anxiety either constitutional or induced by poor psychological management.

The less severe pains occurring more generally probably differ from the causalgic state in degree rather than nature. All tend slowly to spontaneous improvement but the explanation of this is not clear.

\section{Histories}

It is difficult to elicit an objective and unbiased history of these events from patients who may view their symptoms as signifying neurotic derangement rather than as a more or less physiological concomitant of profound anatomical change. Accordingly, case histories have been carefully taken from five men known to the writer personally, two of them for over ten years. All five are highly intelligent, co-operative, free from neurotic personality traits, and they have spoken freely in the knowledge that their symptoms are accepted as being very real. Their own descriptions are quoted. These have been edited only for the sake of brevity.

\section{Patient One}

Accountant, aged 30 . A very good witness who received a burst of machine gun fire in the left arm between the shoulder and elbow on April 
16, 1944. No pain was noted immediately, only marked coldness of the arm, but by the time he reached the Casualty Reception Station nine hours later, pain was most intense. The arm was amputated in the mid-humeral region almost at once. In the post-operative period the stump was extremely painful, and after 14 days the phantom pains appeared. These were irritating and cramplike, and could be relieved temporarily by 'moving' the phantom to a more comfortable position. Later a feeling developed that the fist was tightly clenched ' and the nails were digging into the flesh. This was a very real pain which no action could alleviate. The only cure was to submerge oneself completely in some occupation so that no other circumstance was felt or appreciated. How often I tried this unsuccessfully and, when successful, as soon as the climax of preoccupation passed, the same tight clenched fist returned.' From then till the end of October, 1944, was by far the worst period for the phantom pains and over two stones in weight were lost. The arm began to shorten but the pains were always there. 'They were not a thing to complain about because, after all, I did not expect a doctor to treat a ghost.'

Thereafter, the shortening continued and the pains steadily lessened in severity. By November, r944, it could be divided into three components.

(I) 'Rheumatic' pains in the shoulder-a sharp piercing pain in the joint occurring in cold weather aggravated by drafts and relieved by massage.

(2) A dull pain confined to the bone and brought on by excessive warmth or cold.

(3) Minor aches similar to those experienced after muscular overwork, ' a stiffness which causes increased pain on movement of the stump, but that very movement will eventually make both pain and stiffness disappear.'

\section{Present Condition, Four Years after Injury}

The phantom is now so short that 'the hand appears immediately after the amputation and yet somehow there seems to be an elbow and a wrist between it and the end of the stump.' The scar is perfectly healed. The only tenderness is caused by a gentle stroke across the scars. A firm touch or moderate bang does not cause any pain. Phantom sensations and minor pains, although no longer troublesome, still persist. In cold weather a sock is worn over the stump, but no other precautions are taken. An artificial limb is not worn.

\section{Patient Two}

Wing Commander, fighter pilot, aged 26. Right great toe shot off in 1940 by cannon fire, the stump being modelled and sutured a few hours later, the metatarsal head remaining intact. The scar healed quickly and there was never any pain but within a fortnight the sensation arose that the missing toe was still present. A year later this feeling persisted though in lesser degree. During this period he frequently stumbled or fell from attempting to turn on the missing member. By the middle of 1942 the phantom was very shrunken, and by 1944 it had virtually disappeared.

\section{Patient Three. Medical student, aged 29}

January, 194I. Compound fracture of right tibia and fibula and right patella from enemy action, followed by amputation four days later at junction of upper and middle third of femur. 'Pain in the stump was intense for about three weeks but its character cannot now be accurately remembered. Phantom pains are, however, clearly recollected as starting about two months after operation and they take two forms :-

'(I) A fairly constant numb sensation.

'(2) A sharp pain, spasmodic and sporadic.

- Originally these appeared to come from the areas where the foot ought to have been but with the knee slightly flexed. Slowly, almost imperceptibly, the sensation grew nearer and nearer to the end of the stump, and for the past four years the phantom foot has been just below and behind the end of the stump.

'(I) The numbing sensation like that of wearing shoes which are too tight appears to come mainly from the toes, the plantar surfaces of the distal phalanges and from the dorsal surface of the foot. 'This sensation, fairly constant, is not noticed when my attention is distracted elsewhere, as when talking or concentrating hard on reading. I can always produce the sensation at will, unlike the pain which I can never produce when I desire to do so.

'Tickling the sole of the left foot produces an unbearable sensation in the phantom foot, almost impossible to describe. It is as if ice-cold water suddenly permeated the whole of my phantom leg, starting proximally and pouring down to pool in the phantom foot. It is only transient, passing off within a few seconds. I cannot produce it at will.

'(2) The spasmodic pain seems to originate at - various sites, most commonly the medial side of the big toe, the ball of the foot, the malleoli. The pain is sometimes severe enough to make me jump or wake me out of sleep. Again there are two elements, a deep pain felt in the bone and fairly constant for about five to six seconds. The other is more superficial and severe, coming in short sharp bursts like machine gun fire, the first twinge being the worst, the others diminishing in intensity and the whole episode lasting only three 
to five seconds, during which the stump sometimes jerks spontaneously.

'These pains, once they start, continue spasmodically for some time, varying from days to hours. I can find no relation to fatigue, exercise or weather variations, and they have altered little in frequency or severity since convalescence, coming on once every four to five weeks.'

No treatment has been employed save analgesics such as codeine, which hàs only a slight effect.

\section{Patient Four. Civil engineer, aged 47}

In 1943 he was involved in a railway accident in the Middle East, being pinned under the wreckage for six hours under particularly distressing circumstances, and receiving compound fractures of both tibiae and fibulae. It was nearly 24 hours before he reached hospital, seriously shocked but never having lost consciousness. After conservative operations on both legs he made a good recovery and was able to deal with some business. Knowing that severe psychical symptoms might follow such an ordeal if the memory were repressed, he deliberately and repeatedly went through all the details of the episode in his mind and has never had any psychological symptoms such as nightmares or phobias from the accident. A fortnight after the accident amputation of the right leg at the junction of the upper and middle thirds was necessary, but the left leg continued to heal satisfactorily. Within 24 hours of the operation, the sensation arose that the leg was still present, painless and outstretched in the bed before him. To convince himself that the leg was absent he repeatedly hit the bedclothes just ahead of the stump. Within two months of the accident he was fit enough to be flown to convalescence in South Africa, where although the left leg was still in plaster he got about and led a very active life mentally.

To this day he is still constantly aware of the presence of the 'phantom,' which is of normal size and shape Icorresponding roughly with the variable position of the artificial limb. Practically from the first pains have been felt in the foot but nowhere else. They are likened to severe pins and needles, coming in five second bursts. Originally fairly frequent, these episodes now occur only about two or three times daily. They may be brought on by strong exertion of. the stump, warmth, jarring or allowing the socket of the, artificial limb to press firmly against the back of the stump. They may be accompanied by spasmodic jerking of the stump or this type of uncontrollable movement may occur alone.

On several occasions the stump has been injured in falls during the course of his arduous outdoor occupation. Pain so caused has always been felt locally and never referred to the phantom.

\section{Patient Five}

Business executive, born 1892 , left Cambridge with a good record to serve in the first world war, receiving injuries in 1916 which necessitated a mid-thigh amputation of the right leg. His memory of these earlier events is not to be trusted, but probably phantom sensations began about a fortnight after amputation, to be followed shortly afterwards by definite severe pain in the foot and, to a lesser exterft, the knee. From then there followed a dismal tale interspersed by various operations for remodelling of the stump and successive neurectomies, all producing relief for a short time only. His intellectual deterioration was marked and like so many sufferers from prolonged pain he developed mild paranoic traits. He saw all too clearly the many faults of society and overlooked its virtues. He quarrelled with wife and family and recently died, a lonely and embittered man.

\section{Discussion}

From consideration of the stories told by other amputees, it is believed that these case histories are entirely typical, differing only in the peculiar circumstances which facilitated the taking of a clearer and fuller account of their symptoms than can be obtained from the ordinary patient.

In case one, a major amputation of the arm, causalgic pains appear to have been fairly severe at one time yet, with the 'shrinkage' of the phantom they have become only a minor source of annoyance. Until this man was directly questioned in 1948 he had never before confided his story to any medical attendant- ' he did not expect a doctor to treat a ghost.' His morale was excellent, his temperament stable and his outlook balanced. He was able to accept his symptoms, knowing from conversation with other amputees in the same ward that tisese symptoms were a fairly common occurrence. He discovered for himself that concentration on other mental activity reduced or obviated sensations of pain, and his recovery has been good. The pain which can now be induced by gentle stroking of the scar bears a strong resemblance to the protopathic pain of incomplete nerve recovery.

Subjects three and five have noticed the close association between uncontrollable stump movement and spasmodic pain which suggest that both arise from bursts of nerve activity, perhaps sympathetic discharge. Whereas subject three has experienced the typical shortening phenomenon, subject five continues to feel his leg as of perfectly normal length and, since he can 'move' the phantom he is able to identify it with his artificial 
limb. It may be that he has retained normal length because at the time of amputation he was over 40 and had led a very active athletic life, so that the image of his limbs was very firmly established in the sensorium. The stump was painless from the first and he made a particularly determined effort to master the use of the artificial limb which has now become incorporated in the modified body image and he may be said to have made a very good recovery. The reference of unpleasant sensations to the phantom (patient three) from stimulation of the opposite foot is most interesting and argues the presence of abnormal foci of activity in the cord, probably the internuncial pool of neurones or possibly at a higher level, so that abnormal reflex mechanisms have been established. It might be argued that symptoms here are sufficiently severe to justify some form of active treatment but in view of the tendency to continued spontaneous improvement, this is not contemplated at present.

Patient five and others like him provide the greatest difficulty. In this, the established causalgic state, one is dealing with a profound psychosomatic disturbance, in which both physical and mental factors operate and adversely affect one another in a vicious circle, so that it is hard to say which of the two is the more important. Sympathetic nerve block earlier in the course of the malady is indicated for such people and should be repeated if necessary. Only when this approach fails should more severe operative measure be undertaken.

\section{Conclusions}

Phantom limb phenomena, in one form or another, are of constant or nearly constant occurrence after major amputations. This is not sufficiently widely appreciated and patients are not taught to expect them. It is therefore almost inevitable that when these sensations are noted by the patient they should act as a source of anxiety and perhaps preoccupation. If he were taught to regard such symptoms as a normal sequel of amputation, which would diminish with the passage of time, the amputee might be saved much distress.

In a large proportion of instances, causalgic symptoms occur in greater or lesser severity. The factors causing them and the mechanism of their production are not yet clear. But since any influence producing sympathetic hyperactivity may aggravate these pains, it is reasonable to suppose that unnecessary anxiety or pain during convalescence may predispose to their development, particularly when it is remembered that it is during this phase of early damage that transmission of impulses from motor to sensory nerves most readily occurs. During this healing stage, the unnecessary movement or handling of the stump is therefore to be avoided. Simple sedation as by phenobarbitone maỳ prove valuable. Reassurance may have to be repeated and every effort should be made to direct the patient's interest to activities such as light occupational therapy as soon as he has recovered from the immediate effects of the operation, always provided that movement of the stump is avoided. He will then be a much happier man than the patient who lies abed meditatively contemplating his stump and his phantom, wondering what it is all about.

\section{Summary}

I. Phantom limb sensations are believed to occur after almost every major amputation and causalgic symptoms of greater or lesser severity are common.

2. These symptoms are not primarily neurotic, though secondary psychological disturbances may follow.

3. The mechanism of their production is outlined, and the probable pathology of causalgia is discussed.

4. Five typical histories are reviewed and discussed.

5. It is emphasized that much needless anxiety is caused to patients by failure to acquaint them with the fact that phantom sensations are a reality and not a product of disordered imagination.

6. Suggestions are made for management during the early convalescent phase.

\section{BIBLIOGRAPHY}

CANNON, W. B. (1929), 'Bodily Changes in Pain, Anger, Fear and Rage.' New York.

COHEN, H. (1947), Lancet, i, 933.

CRAIG, J. D. (1948), Lancet, i, 497.

DOUPE, J., CULLEN, C. H. and CHANCE, C. G. (1944), $\boldsymbol{f}$. Neurology, Neuro-Surgery and Psychiatry, 7, 33.

GRANIT, R., KEKSELL, L. and SKOGLUND, C. R. (1944), Brain, 67, 125 .

HEAD, H. and HOLMES, G. M. (r9 I1), Brain, 34, 102.

LERICHE, R. (1940), 'The Surgery of Pain,' (Trans. A. Young.) London.

LERICHE, R. and FONTAINE, R. (1929), Lyon Chir., 26, 323. LEWIS, T. (1936), 'Peripheral Vascular Disorders.' London.

LIVINGSTONE, W. K. (1938), Arch. Surg., 37, 353.

LIVINGSTONE, W. K. (1943), 'Pain Mechanisms.' New York. MITCHELL, S. W., MOORHOUSE and KEEN (1864), 'Gunshot Wounds and other Injuries of Nerves.' Philadelphia.

NATHAN, P. W. (1947), Brain, 70, 145.

PERKINS, G. (1944), Brit. F. Surg., 31, 377.

RIDDOCH, G. (194I), Brain, 64, 197.

SHERRINGTON, C. S. (1906), 'Integrative Action of the Central Nervous System.' New York. 